\title{
Potential anti-inflammatory activity of low molecular weight heparin in patients with exacerbations of COPD - short report
}

\begin{abstract}
Introduction. Anti-inflammatory, separate from anti-thrombotic activity of low molecular weight heparin, is still not well documented.

Aim. We estimated the influence of enoxaparin on serum levels of tumor necrosis factor alpha, as the pro-inflammatory cytokine, and interleukin-12, as the heparin-binding, anti-inflammatory cytokine, in patients with exacerbations of chronic obstructive pulmonary disease.

Material and methods. Seventy-three consecutive patients (48 males, 25 females) aged 56-75 years without thromboembolic history, were enrolled into the study. They were randomized to group who received enoxaparin in one daily dose $40 \mathrm{mg}$, or to group who did not receive it. Patients receiving oral anti-coagulants were excluded from the study. Using ELISA approach, we evaluated serum levels of tumor necrosis factor-alpha and interleukin-12 at the following periods: before the first dose of enoxaparin, after 7 days of treatment and 14 days of treatment. Serum level of the C-reactive protein was evaluated simultaneously.

Results. In enoxaparin recipients statistically significant $(\mathrm{p}<0.01)$ decreasing of TNF-alpha serum levels (from $168.33 \mathrm{pg} / \mathrm{ml}$ in admission, to $85.67 \mathrm{pg} / \mathrm{ml}$ in the end of study) to compare enoxaparine non-recipients, was observed. Interleukin-12 serum levels were significantly higher in enoxaparine recipients both after 7 days $(67.46 \mathrm{pg} / \mathrm{ml})$ and $14 \mathrm{days}(89.32 \mathrm{pg} / \mathrm{ml})$ of the study $(\mathrm{p}<0.05)$. C-reactive proteins serum levels were significantly higher in enoxaparine non-recipients than recipients $(\mathrm{p}<0.05)$ in all study period.

Conclusions. Enoxaparin in daily dose $40 \mathrm{mg}$, significantly depressed serum levels of TNF-alpha and promote serum levels of interleukin-12. Enoxaparin administration may be beneficial for the patients with COPD exacerbation during the first 14 days of treatment.
\end{abstract}

Keywords: low molecular weight heparin, chronic obstructive pulmonary disease exacerbation, IL-12, TNF-alpha, inflammation.

DOI: $10.2478 /$ pjph-2014-0010

\section{INTRODUCTION}

Chronic obstructive pulmonary disease (COPD) represents an increasing epidemiological problem throughout the world. Exacerbations of COPD cause high number of hospital admissions, morbidity, mortality and influence on health-related quality of live [1,2]. There is urgent need of novel therapeutic options to modify inflammation during COPD [3]. Exacerbations of COPD is associated with local and systemic inflammatory response with elevated levels of circulating inflammatory cytokines and acute phase proteins $[4,5]$.

The course of inflammation in COPD exacerbation is determined by the balance between pro-inflammatory and anti-inflammatory mediators including tumor necrosis factor alpha (TNF-alpha) and interleukin-12 (IL-12) and activa- tion of non-specific mediators like C-reactive proteins [6]. Anti-coagulant properties of heparin are well known, but its anti-inflammatory effects are not well documented. Potential mechanisms by which heparin can exert its anti-inflammatory activity are still discussed [7]. Anti-inflammatory properties of heparin are considered to be a result of its ability to bind and inhibit the activity of inflammatory mediators as well as directly inhibiting of inflammatory cells activity [8].The pro-inflammatory cytokine: TNF-alpha is one of the main mediators of cell- mediated lung injury in COPD [9]. The anti-inflammatory cytokine: IL-12 is secreted by peripheral lymphocytes after induction. The most powerful inducers of IL-12 secretion are bacteria and bacterial products. IL-12 appears to bind to heparin with particularly high affinity [10].

\footnotetext{
${ }^{1}$ Department of Pulmonology, Oncology and Allergology, Medical University of Lublin, Poland

${ }^{2}$ Department of Dermatology, Venerology and Paediatric Dermatology, Medical University of Lublin, Poland

${ }^{3}$ Trainee doctor, extern; Independent NHS Clinical Hospital No. 4, Lublin, Poland
} 
In the recent study, we investigated an influence of enoxaparin on serum levels of TNF-alpha and IL-12, in COPD exacerbations, in humans. C-reactive proteins (CRP) serum levels were also estimated simultaneously.

\section{AIM}

We estimated an influence of enoxaparin on serum levels of tumor necrosis factor alpha, as the pro-inflammatory cytokine and interleukin-12, as the heparin-binding, antiinflammatory cytokine, in exacerbations of chronic obstructive pulmonary disease, in humans.

\section{MATERIAL AND METHODS}

We enrolled to the study 73 patients (48 males, 25 females) aged 56-75 years, with COPD exacerbations. The study was approved by an institutional review board bound by the Declaration of Helsinki [11]. All patients were volunteers and each person had written and signed patient's informed consent before entering the study. To participate in the study, patients needed to have moderate to severe COPD, based on the Global Obstructive Lung Disease scale [12]. Patients with very severe COPD exacerbations, with respiratory failure requiring intubation, and severe organ failure, were excluded from the study.

Seventy-three consecutive patients with COPD exacerbation were randomized into two groups: heparin-recipients (37 persons) and heparin non-recipients (36 persons). Concomitant medications included intravenous administration of antibiotics, according to sensitivity of pathogens obtained from sputum smear, theophylline in proper doses per $\mathrm{kg}$ of body mass, inhaled short and long-acting beta-mimetics, inhaled anti-cholinergic drugs in stable doses during the all study period. Heparin-recipients received $40 \mathrm{mg}$ enoxaparin in once daily dose, subcutaneously. The duration of study was 14 days. Serum samples were obtained from both study groups and collected just before initiating treatment and after 7 and 14 days of treatment. Serum concentrations of TNFalpha were determined by ELISA kit (Genzyme Diagnostics, Cambridge) with minimal detection limit $5 \mathrm{pg} / \mathrm{ml}$ and curve range from zero to $500 \mathrm{pg} / \mathrm{ml}$ and lower limit sensitivity at $10 \mathrm{pg} / \mathrm{ml}$. Serum levels of IL-12 were measured by ELISA kit (Genzyme Diagnostics, GBL) with the lower limit sensitivity of the assay: $20 \mathrm{pg} / \mathrm{ml}$. C-reactive proteins serum levels were measured by C-Reactive Protein ELISA kit with lower limit sensitivity $10 \mathrm{pg} / \mathrm{ml}$. All serum samples were randomly assigned code numbers and assayed in a single batch without the knowledge of the clinical status of patient or stage of treatment (heparin recipients or non-recipients). The data obtained from the study were expressed as the mean values with standard deviation. Statistical differences between two study groups were described by Student's t-test with the fiducially limit being $p=0.05$. Serial changes of TNF-alpha, IL-12 and CRP serum levels were examined by analysis of variance and any significance was further sought by least significance difference. Repeated measures analysis of variance test was used to compare serum levels of IL-12, TNFalpha and CRP with baseline values just before treatment and after 7 and 14 days of treatment, within each study group and between two study groups (enoxaparin-recipients and enoxaparin non-recipients) in each study period.

\section{RESULTS}

In both study groups we observed statistically significant gradual decreasing of TNF-alpha serum levels during all the study period, to compare period before treatment initiation: $168.33 \mathrm{pg} / \mathrm{ml}(\mathrm{p}<0.01$; SD $+/-2.78)$. This gradual decline was significantly deeper in heparin recipients $(98.62 \mathrm{pg} / \mathrm{ml}$ after 7 days and $85.67 \mathrm{pg} / \mathrm{ml}$ after 14 days of treatment) to compare heparin non-recipients $(126.33 \mathrm{pg} / \mathrm{ml}$ after 7 days and $102.82 \mathrm{pg} / \mathrm{ml}$ after 14 days of study), $\mathrm{p}<0.05$. These results are illustrated on Figure 1.

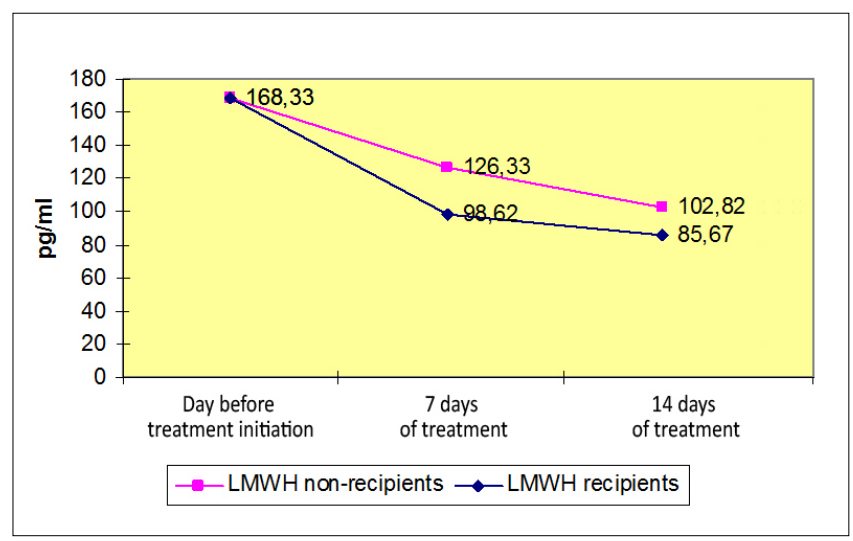

FIGURE 1. The mean values of TNF-alpha serum levels in heparinrecipients and heparin non-recipients in COPD exacerbation, during the 14 days of treatment.

IL-12 serum levels were significantly higher in heparin-recipients both after 7 days of treatment $(67.46 \mathrm{pg} / \mathrm{ml}$, $\mathrm{SD}+/-3.30 \mathrm{pg} / \mathrm{ml})$ and 14 days of treatment $(89.32 \mathrm{pg} / \mathrm{ml}$, $\mathrm{SD}+/-3.8)$ to compare heparin non-recipients $(52.32 \mathrm{pg} / \mathrm{ml}$, $\mathrm{SD}+/-2.35)$ after 7 days of treatment and after 14 days of treatment $(58.44 \mathrm{pg} / \mathrm{ml}, \mathrm{SD}+/-3.35), \mathrm{p}<0.05$. These results are illustrated on Figure 2.

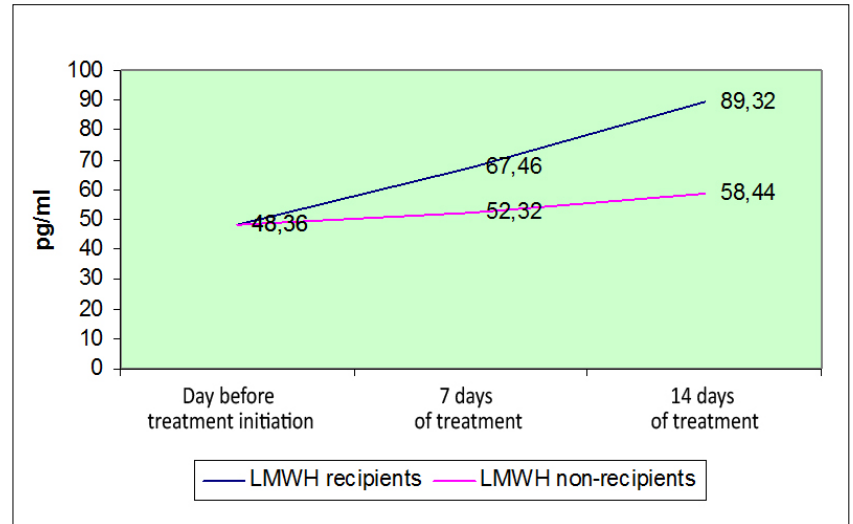

FIGURE 2. The mean values of IL-12 serum levels in heparin-recipients and heparin non-recipients in COPD exacerbation, during the 14 days of treatment.

CRP serum levels were significantly higher in enoxaparin non-recipients to compare enoxaparin non-recipients in each study period $(\mathrm{p}<0.05)$. After 14 days of treatment significant deep decline of CRP serum level in heparinrecipients $(45.136 \mathrm{pg} / \mathrm{ml}, \mathrm{SD}+/-3.52)$ to compare the day 


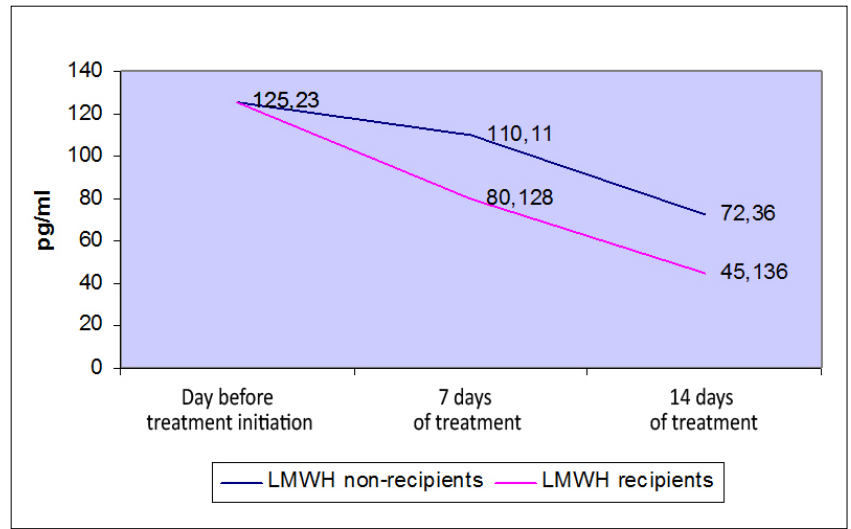

FIGURE 3. The mean values of CRP serum levels in heparin-recipients and heparin non-recipients in COPD exacerbation, during the 14 days of treatment.

entry of study $(125.23 \mathrm{pg} / \mathrm{ml}, \mathrm{SD}+/-4.2) \mathrm{p}<0.05$ within this group. These results are illustrated on Figure 3.

\section{DISCUSSION AND CONCLUSIONS}

Low molecular weight heparin has a wide range of clinical applications [13,14]. Anti-inflammatory activity of low molecular weight heparin includes inhibition of inflammatory cells, inhibition of inflammatory mediators and stabilization of blood vessel wall [15]. Only $1 / 3$ of heparin molecules possesses anti-coagulant activity. The rest $2 / 3$ of heparin molecules is unlikely to be an anticoagulant [16]. Effects with potential anti-inflammatory applications of low molecular weight heparin include the inhibition and adhesion of neutrophils to vascular endothelium [17]. It has been evidenced that elevated systemic inflammatory mediators are responsible for reduced lung function during COPD exacerbation [18].

In the recent study, we observed significantly higher IL-12 serum levels, as heparin-binding, anti-inflammatory cytokine, both after 7 days and 14 days of observation, in patients who received enoxaparin in dose $40 \mathrm{mg}$ daily, to compare with patients who did not receive it. Simultaneously, significantly deeper decline of TNF-alpha serum levels in heparin-recipients to compare with non-recipients, during the all study period, occurred. The results of our study were similar to the other investigations which evidenced that enoxaparin has been shown to potently inhibit TNF-alpha production by vascular endothelial cells during inflammatory process [19]. On the other hand, deep depression of inflammatory cells by enoxaparin may promote infectiondepended lung injury, because inflammatory cells play a role in host defense mechanisms in COPD exacerbation.

\section{REFERENCES}

1. Sin DD, Anthonisen NR, Soriano JB, et al. Role of comorbidities. Eur Resp J. 2006;28(6):1245-57.

2. Wedzicha JA, Donaldson GC. Exacerbations of chronic obstructive pulmonary disease. Respir Care. 2003;48(12):1204-13.

3. Bathroorn E, Huib K, Postma D, et al. Airways inflammation and treatment during acute exacerbations of COPD. Int J Chron Obstruct Pulmon Dis. 2008;3(2):217-29.

4. Hurst JR, Perera WR, Wilkinson TM, et al. Systemic and upper and lower airway inflammation at exacerbation of chronic obstructive pulmonary disease. Am J Resp Crit Care Med. 2006;173(1):71-8.

5. Wounters EF. Local and systemic inflammation in chronic obstructive pulmonary disease. Proc Am Thorac Soc. 2005;2(1):26-33.

6. Gan WQ, Man SF, Sethilselvan A, Sin DD. Association between chronic obstructive pulmonary disease ans systemic inflammation: a review ans meta-analysis. Thorax. 2004;59:574-80

7. Young E. The anti-inflammatory effects of heparin and related compounds. Thromb Res. 2008;122(6):743-52.

8. Tyrell DJ, Home AP, Holme R, et al. Heparin in inflammation: potential therapeutic applications beyond anticoagulation. Adv Pharmacol. 1999;46:151-208

9. Yoshida T, Tuder MR. Pathobiology of cigarette smoke-induced chronic obstructive pulmonary disease. Physiol Rev. 2007;87:1047-82.

10. Hasan M, Najjam S, Gorgon MY, et al. IL-12 is a heparin-binding cytokine. J Immunol. 1999;162:1064-70.

11. World Medical Association Declaration of Helsinki Ethical Principles for Medical Research Involving Human Subjects. 59 WMA General Assembly, Seoul, October 2008.

12. Global Initiative for Lung Disease, Bethesda. Global Obstructive Lung Disease 2008.

13. Green D, Hirsh J, Heit J et al. Low-molecular-weight heparin: a critical analysis of clinical trials. Pharmacol Rev. 1994;46:89-109.

14. Lianchun W, Jilian RB, Ajit V, Jeffrey DE. Heparin's anti-inflammatory effects require glucosamine 6-0-desulphation and are mediated by blockade of L- and p-selections. J Clin Invest. 2002;110:127-36.

15. Terranova VP, Difloria R, Lyall RM, et al. Human endothelial cells are chemotactic to endothelial cell growth factor and heparin. J Cell Biol. 1985;101:2330-4

16. Parish DR, Coom DR, Jacobsen KB, et al. Evidence that sulfated polysaccharides inhibit tumor metastasis by blocking tumor -cell- derived heparinases. Int J Cancer.1987;40:511-8.

17. Brown RA, Leveb R, Jones NA Page CO. Effects of heparin and related molecules upon neutrophil aggregation and elastase release in vitro. $\mathrm{Br} \mathrm{J}$ Pharmacol. 2003;139:845-53.

18. Seemungal T, Harper-Owen R, Bhowmik A, et al. Respiratory viruses, symptoms and inflammatory markers in acute and stable chronic obstructive lung disease. Am J Respir Crit Care Med. 2001;164:1618-23.

19. Van MX, Liu G, Wang Y, Thorlacius H. Protective effect of low molecular weight heparin on experimental colitis: role of neutrophil recruitment and TNF-alpha production. Inflamm Res. 2002;51:182-7.

This study was presented during the ERS Vienna 2009 Congress as an oral presentation. The abstract has been published in European Respiratory Journal, September 2009, vol 34, suppl 53.

\author{
Corresponding author \\ Barbara Rybacka-Chabros \\ Department of Pulmonology, Allergology and Oncology, \\ Medical University of Lublin \\ 8 Jaczewskiego Str., 20-950 Lublin, Poland \\ tel : +48 81 742-44-31, +48 510-973-716 \\ E-mail: doctor_86@o2.pl
}

